\title{
The Bottom Up Approach is Not Always the Best Processing Method: Dense $\alpha-\mathrm{Al}_{2} \mathrm{O}_{3} / \mathrm{NiAl}_{2} \mathrm{O}_{4}$ Composites
}

\author{
Nathan J. Taylor, Andrew J. Pottebaum, Veli Uz, and Richard M. Laine**
}

The bottom up approach suggests that atomic scale mixing should permit optimal control of processing for many types of materials in terms of densification rates, final and average grain sizes; and, thereafter, global properties thereby minimizing processing conditions, capital equipment requirements, and energy consumption. The literature indicates that, to date, this axiom has not been tested although numerous researchers have whole-heartedly adopted the concept. Liquid-feed flame spray pyrolysis (LF-FSP) provides atomically mixed $\mathrm{NiO} \cdot 3 \mathrm{Al}_{2} \mathrm{O}_{3}$ nanopowders $(30-40 \mathrm{~nm}$ average particle size, APS) that are a single phase, spinel solid solution. Sintering $56 \pm 1$ wt $\%$ CIPped pellets to $95 \pm 1 \%$ theoretical density using two different heating schedules produces $\alpha-\mathrm{Al}_{2} \mathrm{O}_{3} / \mathrm{NiAl}_{2} \mathrm{O}_{4}$ composites with grain sizes of $0.9 \pm$ $0.2 \mu \mathrm{m}$. For comparative purposes, ball milled $\mathrm{Al}_{2} \mathrm{O}_{3}$ are synthesized from both highly atomically-mixed single phase metastable spinel nanopowders and $\mathrm{NiAl}_{2} \mathrm{O}_{4} 30-40 \mathrm{~nm}$ APS pellets of the same composition with a submicrometer length scale mixing and similar green densities are also sintered to $95 \pm 2 \%$ TD. In both instances, the same microstructures are realized despite the great difference in length scale of mixing. This contrasts greatly with the expectation that the atomically mixed materials would give finer grain sizes at the same densities and with faster sintering times, suggesting that the bottom up approach is not always valid.

\section{Introduction}

A long-standing concept in materials processing is that material properties can be improved by starting with better and finer mixing of reactive components. ${ }^{[1-5]}$ Mixing at finer length scales is also thought to provide better control of final microstructural properties, which in turn can lead to better control of macroscopic (global) properties. ${ }^{[6-8]}$ To take full advantage of this bottom-up approach, one can suggest that true atomic scale mixing should provide optimal control of microstructural evolution and compositional control at the finest feature sizes.

In the field of ceramics processing, where the energetics of sintering require extended periods at high temperatures to activate diffusion processes, the bottom-up concept appears to be the best approach to obtaining high quality monoliths with exceptional control of densities and final grain sizes. While the

N. J. Taylor, A. J. Pottebaum, V. Uz, Prof. R. M. Laine Department of Materials Science and Engineering University of Michigan

Ann Arbor, MI 48109-2136

E-mail: talsdad@umich.edu

DOI: 10.1002/adfm.201302845 axiomatic bottom-up approach is often applied to the synthesis of nanostructured devices, surprisingly; the effect of the bottom-up approach on the synthesis of bulk materials has yet to be investigated. Applied to composite systems of two or more phases, our expectation was that starting from the bottom-up, the densest composites with the finest grain sizes would obtain from atomically mixed metastable nanopowders.

Liquid-feed flame spray pyrolysis (LFFSP) involves the combustion of alcohol solutions of simple metalloorganic precursors such as carboxylates, alkoxides, or $\beta$-diketonates. ${ }^{[9-12]}$ The resultant metal oxide or mixed-metal oxide nanopowder "soot" is quenched rapidly at rates $>1000{ }^{\circ} \mathrm{C} \mathrm{s}^{-1}$ and collected $1.5 \mathrm{~m}$ downstream in electrostatic precipitators at rates of up to $100 \mathrm{~g} \mathrm{~h}^{-1}$. LF-FSP gas phase particle production has the advantage of producing oxide nanopowders with nearly perfect atomic mixing and access to exact stoichiometries. We have previously synthesized a number of phase pure, metastable spinels with atomic scale elemental mixing at compositions well outside the normally reported phase fields..$^{[9-12]}$ We have also reported the synthesis of fine grained composite materials such as $\mathrm{t}-\mathrm{ZrO}_{2}$ $\alpha-\mathrm{Al}_{2} \mathrm{O}_{3}$ materials that exhibit enhanced mechanical properties. ${ }^{[13]}$

Spinels are a class of transition metal oxides with the general structure $\mathrm{AB}_{2} \mathrm{O}_{3}$. The spinel structure consists of an FCC oxygen sublattice with cations occupying $1 / 8$ the tetrahedral sites and $1 / 2$ the octahedral sites. In the normal spinel structure, the $\mathrm{B}^{3+}$ cations occupy the octahedral sites with the $\mathrm{A}^{2+}$ cations occupying the tetrahedral sites. In the inverse spinel structure, the divalent cations occupy the octahedral sites, while the trivalent cations occupy the tetrahedral sites. ${ }^{[14]}$ In addition, many spinels exist with mixed character, leading to the general formula $\left(\mathrm{A}_{1-x} \mathrm{~B}_{x}\right)\left[\mathrm{A}_{x} \mathrm{~B}_{2-x} \mathrm{O}_{4}\right]$ with $\left(\mathrm{A}_{1-x} \mathrm{~B}_{x}\right)$ indicating tetrahedral occupancy and $\left[\mathrm{A}_{x} \mathrm{~B}_{2-x} \mathrm{O}_{4}\right]$ representing octahedral occupancy, where $\mathrm{x}$ represents the degree of inversion. The determination of the spinel inversion parameter across many systems has been a common academic exercise. ${ }^{[15]}$

Taking into account electrostatic interactions, atomic radii, and ligand field effects, $\mathrm{Ni}$ is commonly reported to have high octahedral site preference energy (OSPE), driving the formation of inverted spinels. ${ }^{[15]}$ As reported in our previous work on $\mathrm{NiO} \cdot 3 \mathrm{Al}_{2} \mathrm{O}_{3}$, the presence of a single phase material requires that some $\mathrm{Al}^{3+}$ cations occupy octahedral sites, leading to a 
mixed spinel. In addition, $\delta-\mathrm{Al}_{2} \mathrm{O}_{3}$ is commonly formed in gas-phase $\mathrm{Al}_{2} \mathrm{O}_{3}$ nanopowder syntheses. ${ }^{[16]} \delta$ - $\mathrm{Al}_{2} \mathrm{O}_{3}$ is normally described as a defect spinel structure, where 8/3 Al tetrahedral vacancies account for spinel cation vacancies. ${ }^{[17]} \mathrm{Al}_{2} \mathrm{O}_{3}$ rich spinel solid solutions have been well characterized in the $\mathrm{MgO}-\mathrm{Al}_{2} \mathrm{O}_{3}$ system, and the corresponding defect reaction can be shown in: ${ }^{[18,19]}$

$4 \mathrm{Al}_{2} \mathrm{O}_{3} \rightarrow V_{N i}^{+} 2 A l_{N i}+6 A l_{A l}^{X}+12 O_{O}^{X}$

Nickel aluminate spinel materials have been explored in considerable detail for multiple reasons. For example, the spinel material is used as a pigment. ${ }^{[20]}$ It is also used as a electrode material in high temperature fuel cells because of its unusual conductivity. ${ }^{[21-23]}$ It is also used as a catalyst or a precatayst for steam reforming. ${ }^{[2,25]} \mathrm{NiAl}_{2} \mathrm{O}_{4}-\mathrm{Al}_{2} \mathrm{O}_{3}$ composites may also have application as a structural ceramic material. ${ }^{[26]}$

The introduction of excess alumina into the nickel aluminate spinel does not significantly change the color of the resulting nanopowder, consequently one might envision using the reduced nickel content materials as replacement pigments, assuming that there is no change in properties when these pigments are used in ceramic glazes for example. As electrode materials, there is interest in making dense materials that retain their mechanical properties, their electrical properties and that also offer thermal stability after continued use in SOFC environments. ${ }^{[22]}$ Finally, steam reforming catalysts are usually nickel on alumina and normally activity will be related to the nickel particle size where smaller particle sizes equal higher catalytic activities. ${ }^{[27]}$ The materials we produce below are dense ceramics but they are oxides and could be reduced for catalytic activity. One can assume that finer grain sizes will lead to smaller Ni particles on reduction that could in principle lead to higher catalytic activity. In addition, the reduction process will produce Ni particles in or on an alumina matrix and will create porosity. While this is not the objective of the current manuscript; all of the above applications will benefit from an understanding of the thermal behavior of the materials produced by the two processing approaches explored here.

\section{Results and Discussion}

The objectives of the work discussed here are to explore the potential utility of using atomically mixed metastable $\mathrm{NiO} \cdot 3 \mathrm{Al}_{2} \mathrm{O}_{3}$ nanopowders (APSs $30-40 \mathrm{~nm}$ ) as a starting point for processing ceramic-ceramic composites with optimal control of the densification process, final average grain sizes and in principle with optimal macroscopic properties. This approach is an effort to test the efficacy of the bottom up approach. To ensure a fair comparison with other processing approaches, we also performed a side-by-side comparison using equivalent composition ball-milled mixtures of $\delta-\mathrm{Al}_{2} \mathrm{O}_{3}$ and $\mathrm{NiAl}_{2} \mathrm{O}_{4}$ (APSs $30-40 \mathrm{~nm}$ for both). In the latter case, ball milling is anticipated to lead to compositional homogeneity only at submicrometer length scales. Thus, there was considerable disparity in the homogeneity length scales in the green state.

We begin by discussing the synthesis and characterization of the powders used in the study through BET surface area
Table 1. BET SSAs and derived APSs for nanopowders used in this study.

\begin{tabular}{lccc}
\hline Powder & $\begin{array}{c}\text { Density } \\
{\left[\mathrm{g} \mathrm{cm}^{-3}\right]}\end{array}$ & $\begin{array}{c}\text { SSA } \\
{\left[\mathrm{m}^{2} \mathrm{~g}^{-1}\right]}\end{array}$ & $\begin{array}{c}\text { APS } \\
{[\mathrm{nm}]}\end{array}$ \\
\hline $\mathrm{NiO} \cdot 3 \mathrm{Al}_{2} \mathrm{O}_{3}$ & 4.16 & 43 & 34 \\
$\mathrm{NiAl}_{2} \mathrm{O}_{4}$ & 4.49 & 42 & 31 \\
$\mathrm{Nanotek}$ & 3.6 & 30 & 56 \\
\hline
\end{tabular}

analysis, SEM, TEM, XRD, and DRIFTS. Thereafter we discuss the results of sintering studies and the final microstructures as shown by SEM of composites prepared from atomically mixed $\mathrm{NiO} \cdot 3 \mathrm{Al}_{2} \mathrm{O}_{3}$ as well as ball-milled two-component mixtures with the same composition.

\subsection{BET Surface Area Analysis}

Specific surface areas (SSAs) for all powders used in this study are listed in Table 1 . No microporosity was detected nor is microporosity common in LF-FSP nanopowders. Average particle sizes (APSs) were calculated from the SSAs using the theoretical densities and assuming spherical powder morphologies. All SSAs are $\pm 1 \mathrm{~m}^{2} \mathrm{~g}^{-1}$, which give APSs within $\pm 2 \mathrm{~nm}$. SSAs were repeatable across different production runs within $\pm 3 \mathrm{~m}^{2} \mathrm{~g}^{-1}$.

\subsection{Scanning Electron Microscopy}

SEM was performed on all as-produced powders to establish overall particle morphology and qualitatively investigate the overall particle size distribution. Figure 1 shows a representative SEM image of as-produced $\mathrm{NiO} \cdot 3 \mathrm{Al}_{2} \mathrm{O}_{3}$. All particles show similar spherical morphology, and appear agglomerated. A few $>100 \mathrm{~nm}$ particles are present, but the majority appear to be

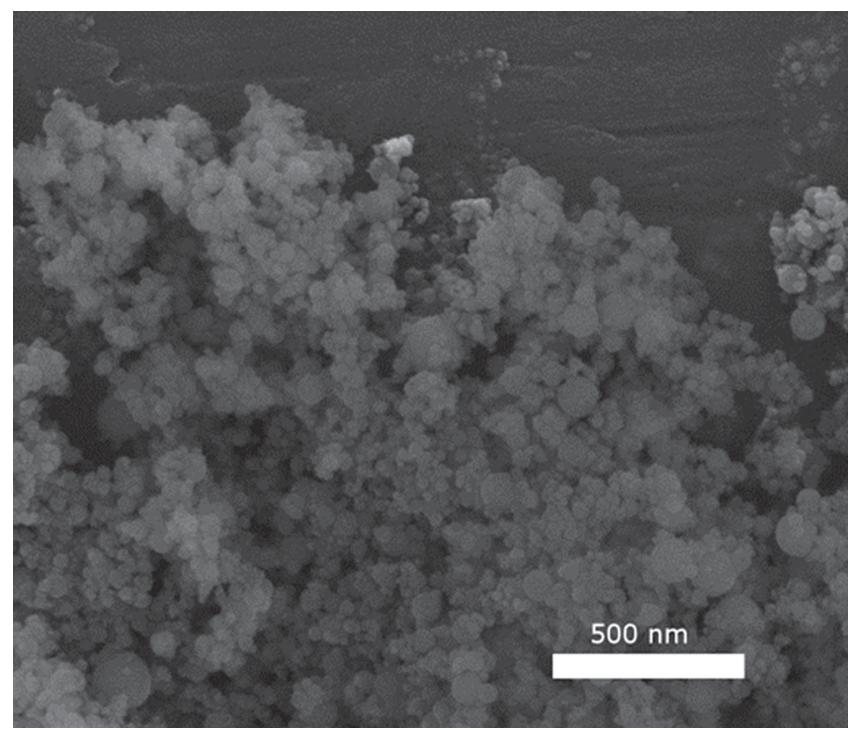

Figure 1. Representative scanning electron micrograph of as-produced $\mathrm{NiO} \cdot 3 \mathrm{Al}_{2} \mathrm{O}_{3}$ nanopowder. Some larger particles are present but the majority agree with BET derived APSs. 


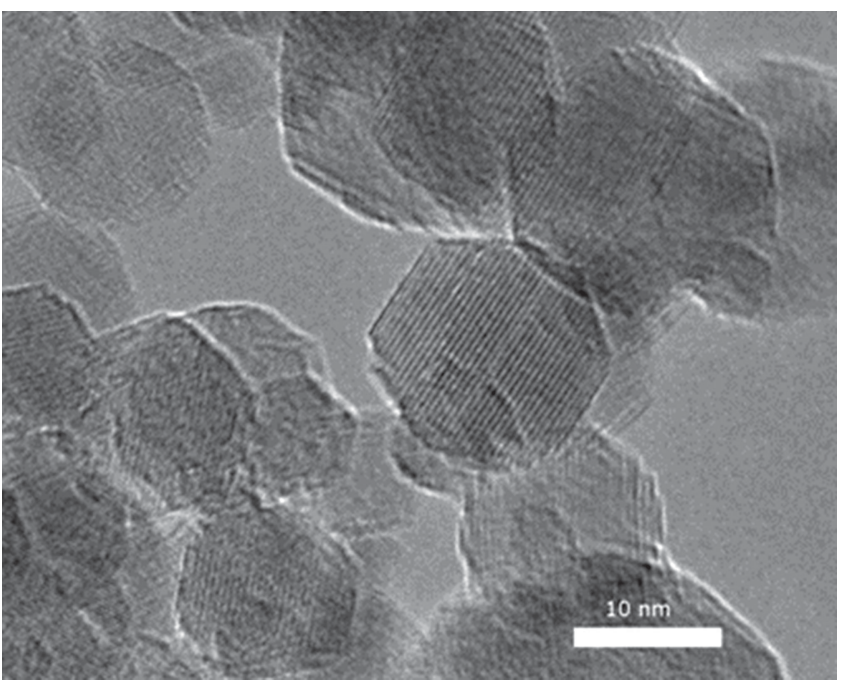

Figure 2. TEM image showing $\mathrm{NiO} \cdot 3 \mathrm{Al}_{2} \mathrm{O}_{3}$. Single crystal particles are faceted and agglomerated. The majority of particles are unaggregated.

$<50 \mathrm{~nm}$, which correlates well with BET derived particle sizes. No fraction of large $>1 \mu \mathrm{m}$ particles were observed by SEM.

\subsection{Transmission Electron Microscopy}

TEM provides more information including particle morphology and degree of aggregation. Figure 2 provides a representative TEM image of as-produced $\mathrm{NiO} \cdot 3 \mathrm{Al}_{2} \mathrm{O}_{3}$. TEM indicates most particles are agglomerated, highly faceted, single crystals. Some aggregates are observed by TEM, but this represents only a small fraction of the particles.

\subsection{X-Ray Diffraction}

As seen in Figure 3, XRD indicates as-produced $\mathrm{NiO} \cdot 3 \mathrm{Al}_{2} \mathrm{O}_{3}$ is a single phase material. $\delta-\mathrm{Al}_{2} \mathrm{O}_{3}$ is isostructural with the spinel structure allowing for ready formation of solid solutions. ${ }^{[17]} \mathrm{Cal}-$ culations provide a lattice constant for as-produced $\mathrm{NiO} \cdot 3 \mathrm{Al}_{2} \mathrm{O}_{3}$ at a point $53 \%$ along the $\mathrm{Al}_{2} \mathrm{O}_{3}-\mathrm{NiAl}_{2} \mathrm{O}_{4}$ tie line (see experimental section) in keeping with Vegard's law, supporting the classification of the atomically mixed, metastable spinel as a $\delta-\mathrm{Al}_{2} \mathrm{O}_{3} / \mathrm{NiAl}_{2} \mathrm{O}_{4}$ solid solution.

XRDs of the as-produced stoichiometric $\mathrm{NiAl}_{2} \mathrm{O}_{4}$ powder find spinel as the primary phase, with some $(<5 \mathrm{wt} \%)$ bunsenite (NiO) (see Supporting Information, Figure S1). The presence of bunsenite remains unexplained, but may relate to the kinetics of the quenching process. However, XRDs of stoichiometric $\mathrm{NiAl}_{2} \mathrm{O}_{4}$ sintered to high temperature $\left(1400{ }^{\circ} \mathrm{C}\right) \mathrm{did}$ not indicate any extraneous phases, so overall, the composition seems to be correct.

On heating $\mathrm{NiO} \cdot 3 \mathrm{Al}_{2} \mathrm{O}_{3}$ powders to the phase transformation temperature for $\alpha-\mathrm{Al}_{2} \mathrm{O}_{3}, 1150{ }^{\circ} \mathrm{C}, \alpha-\mathrm{Al}_{2} \mathrm{O}_{3}$ nucleates from $\mathrm{Al}_{2} \mathrm{O}_{3}$ rich spinel. ${ }^{[17]}$ Figure 4 shows TGA-DTA, indicating a phase transformation temperature of $1205^{\circ} \mathrm{C}$. This temperature lies above some more common $\alpha$-transformation temperatures, and $\approx 45{ }^{\circ} \mathrm{C}$ less than the DTA exotherm corresponding to $\alpha$ - $\mathrm{Al}_{2} \mathrm{O}_{3}$

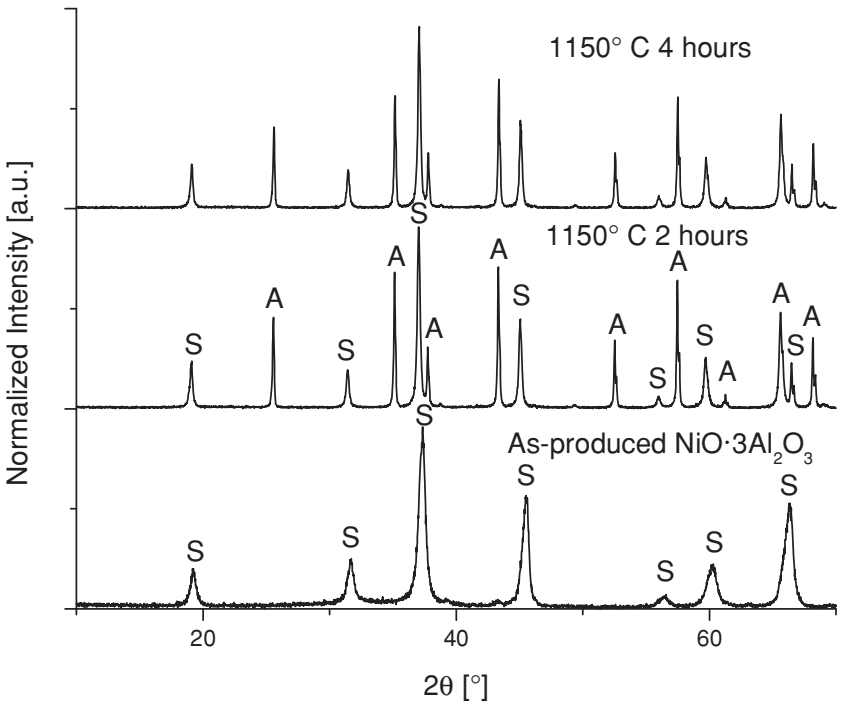

Figure 3. XRD spectra for as-produced $\mathrm{NiO} \cdot 3 \mathrm{Al}_{2} \mathrm{O}_{3}$ as well as samples heated for two and four hours at $1150{ }^{\circ} \mathrm{C}$. $\left(\mathrm{A}=\alpha-\mathrm{Al}_{2} \mathrm{O}_{3}, \mathrm{~S}=\mathrm{NiAl}_{2} \mathrm{O}_{4}\right.$ spinel) The as-produced sample is single phase corresponding to $\mathrm{NiAl}_{2} \mathrm{O}_{4}$. The calcined samples indicate segregation of $\alpha-\mathrm{Al}_{2} \mathrm{O}_{3}$.

transformation for Nanotek $\mathrm{Al}_{2} \mathrm{O}_{3}$ (SI, Figure S2). The lower exotherm is likely an effect of $\mathrm{Ni}$ doping, which has been shown to reduce the $\alpha$-transformation temperature. ${ }^{[29]}$ TGA mass loss above $1200{ }^{\circ} \mathrm{C}$ can be attributed to the slight volatility of $\mathrm{NiO} \cdot{ }^{[30]}$ Figure 3 presents XRDs for as-produced $\mathrm{NiO} \cdot 3 \mathrm{Al}_{2} \mathrm{O}_{3}$ powder and samples heated to $1150{ }^{\circ} \mathrm{C}$ for 2 and $4 \mathrm{~h}$. The only phase present for as-produced $\mathrm{NiO} \cdot 3 \mathrm{Al}_{2} \mathrm{O}_{3}$ is identical to $\mathrm{NiAl}_{2} \mathrm{O}_{4}$ spinel (PDF: 01-071-0963). After heating to $1150{ }^{\circ} \mathrm{C}, \alpha-\mathrm{Al}_{2} \mathrm{O}_{3}$ (PDF: 01-078-2427) appears. Further heating does not increase the $\alpha-\mathrm{Al}_{2} \mathrm{O}_{3}$ content indicating that $2 \mathrm{~h} / 1150{ }^{\circ} \mathrm{C}$ is sufficient for full phase segregation. XRD shows Nanotek is a mixed transition- $\mathrm{Al}_{2} \mathrm{O}_{3}$, consisting of $\delta, \delta^{*}$, and $\theta-\mathrm{Al}_{2} \mathrm{O}_{3}$.

The Figure 5 SEM shows a fracture surface after heating as-produced $\mathrm{NiO} \cdot 3 \mathrm{Al}_{2} \mathrm{O}_{3}$ pellet to $1150{ }^{\circ} \mathrm{C} / 4 \mathrm{~h} /$ air. Large islands $>200 \mathrm{~nm}$ of $\alpha-\mathrm{Al}_{2} \mathrm{O}_{3}$ have formed within the spinel (now primarily $\mathrm{NiAl}_{2} \mathrm{O}_{4}$ ) matrix, which undergoes little grain growth. These islands were confirmed to be $\alpha-\mathrm{Al}_{2} \mathrm{O}_{3}$ by EDS

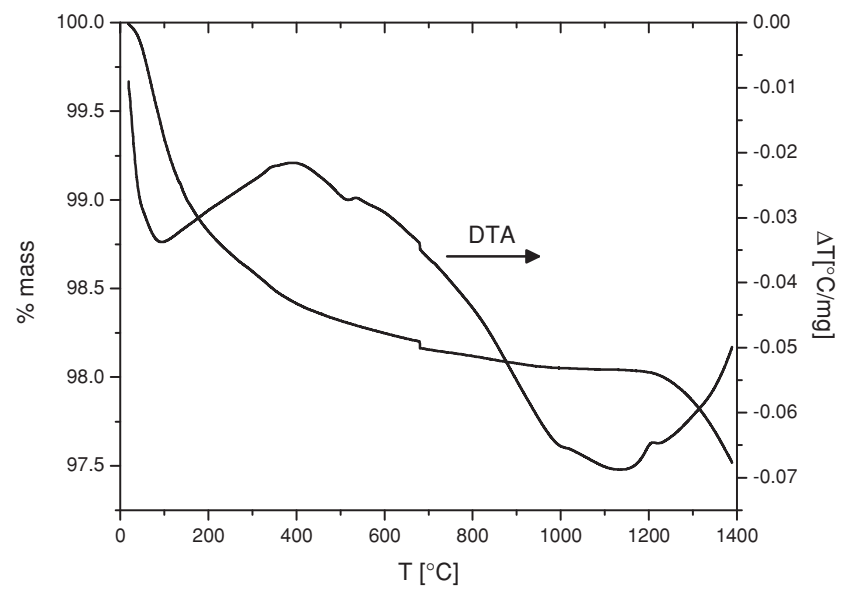

Figure 4. TGA/DTA traces for as-produced $\mathrm{NiO} \cdot 3 \mathrm{Al}_{2} \mathrm{O}_{3}$. 


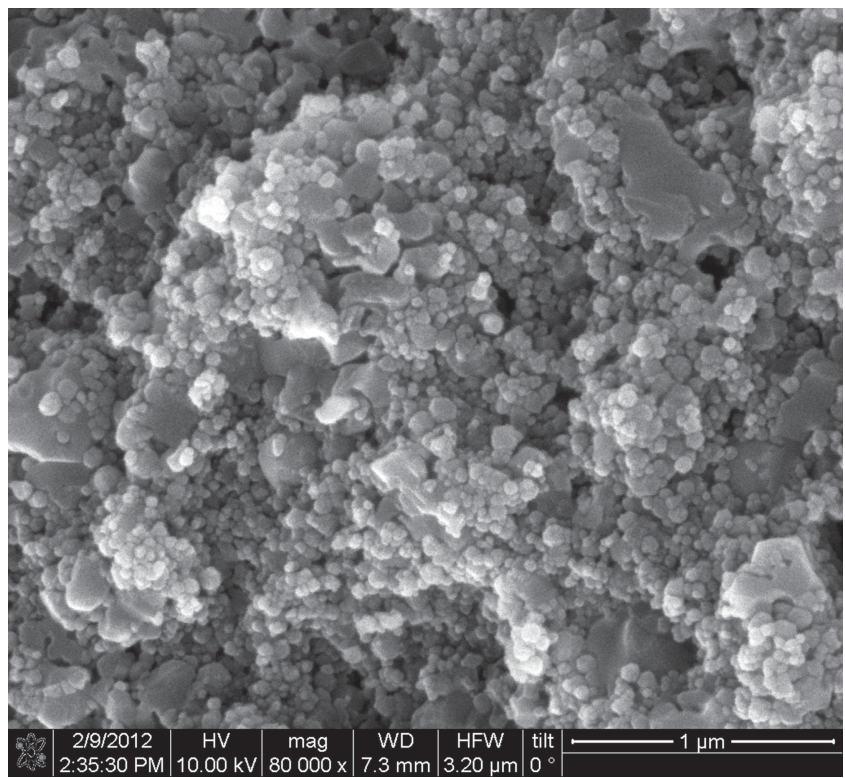

Figure 5. SEM image of demixed sample heated to $1150{ }^{\circ} \mathrm{C}$ for $2 \mathrm{~h} /$ air. The large grains are $\alpha-\mathrm{Al}_{2} \mathrm{O}_{3}$, while the spinel particles have barely coarsened.

and Scherrer line broadening. It is important to note that no transition- $\mathrm{Al}_{2} \mathrm{O}_{3}$ phases were observed prior to $\alpha-\mathrm{Al}_{2} \mathrm{O}_{3}$ segregation. The transformation sequence of the defect spinel, $\gamma-\mathrm{Al}_{2} \mathrm{O}_{3}$, involves transformation through both the $\delta$ and $\theta$ phases prior to transformation to the $\alpha-\mathrm{Al}_{2} \mathrm{O}_{3}$ phase. ${ }^{[17]}$ This observation suggests no segregation of $\mathrm{Al}_{2} \mathrm{O}_{3}$ exists prior to nucleation of the $\alpha-\mathrm{Al}_{2} \mathrm{O}_{3}$ phase, which means the driving force for $\mathrm{Al}_{2} \mathrm{O}_{3}$ segregation appears to be $\alpha-\mathrm{Al}_{2} \mathrm{O}_{3}$ nucleation.

\subsection{DRIFTS}

Spectra for as-produced $\mathrm{NiO} \cdot 3 \mathrm{Al}_{2} \mathrm{O}_{3}$ as well as a sample heated to $1150{ }^{\circ} \mathrm{C} / 2 \mathrm{~h} /$ air/ $10{ }^{\circ} \mathrm{C} \mathrm{min}-1$, LF-FSP $\mathrm{NiAl}_{2} \mathrm{O}_{4}$, and Nanotek $\mathrm{Al}_{2} \mathrm{O}_{3}$ are presented in Figure 6. The $1800-4000 \mathrm{~cm}^{-1}$ region is magnified 10x. The broad $v \mathrm{OH} 3700-2500 \mathrm{~cm}^{-1}$ band corresponds to both physi- and chemi-sorbed water and is typical for LF-FSP nanopowders. These species are not seen in the $1150{ }^{\circ} \mathrm{C} \mathrm{NiO} \cdot 3 \mathrm{Al}_{2} \mathrm{O}_{3}$ FTIR. The $1000-400 \mathrm{~cm}^{-1}$ region exhibits $v \mathrm{M}-\mathrm{O}$ absorptions bands with a $v$ Ni-O peak at $500 \mathrm{~cm}^{-1} \cdot{ }^{[1]}$ Peaks near 600 and $800 \mathrm{~cm}^{-1}$ correspond to octahedrally and tetrahedrally coordinated $v \mathrm{Al}-\mathrm{O}$ respectively, and are present in all samples. ${ }^{[26]}$

The observation of mixed octahedral/tetrahedral $v \mathrm{Al}-\mathrm{O}$ bands in as-produced material is indicative of a highly disordered spinel structure (elemental mixing at atomic length scales). Peak narrowing coincident with increased relative intensity of the $600 \mathrm{~cm}^{-1}$ with respect to the $800 \mathrm{~cm}^{-1}$ peak in the $1150{ }^{\circ} \mathrm{C}$ material is a consequence of $\alpha-\mathrm{Al}_{2} \mathrm{O}_{3}$ nucleation as it contains only $\mathrm{AlO}_{6}$ octahedra. Nanotek $\mathrm{Al}_{2} \mathrm{O}_{3}$ shows peaks at 600 and $800 \mathrm{~cm}^{-1}$, characteristic for $v \mathrm{Al}-\mathrm{O}$ octahedral and tetrahedral environments, respectively, along with a broad $v \mathrm{OH}$ peak. ${ }^{[31]}$ Figure 4 provides a TGA/DTA showing a $1.9 \mathrm{wt} \%$ mass loss at $1100{ }^{\circ} \mathrm{C}$, consistent with the loss of chemisorbed water and $\mathrm{CO}_{2}$ as observed in the DRIFT spectra. TGA/DTA traces of $\mathrm{NiAl}_{2} \mathrm{O}_{4}$ and Nanotek $\mathrm{Al}_{2} \mathrm{O}_{3}$ (Figure S2) show similar mass losses $<3 \mathrm{wt} \%$ corresponding to elimination of surface hydroxyls and traces of $\mathrm{CO}_{2}$.

Drawing on the phase separation behavior exhibited by the metastable particles, we began to process $\mathrm{NiO} \cdot 3 \mathrm{Al}_{2} \mathrm{O}_{3}$ into compacts to produce $\alpha-\mathrm{Al}_{2} \mathrm{O}_{3} / \mathrm{NiAl}_{2} \mathrm{O}_{4}$ composite materials. The exact composition was also matched by ball milling of stoichiometric LF-FSP $\mathrm{NiAl}_{2} \mathrm{O}_{4}$ nanopowder with commercial Nanotek $\mathrm{Al}_{2} \mathrm{O}_{3}$ nanopowder to produce a $\mathrm{NiO} \cdot 3 \mathrm{Al}_{2} \mathrm{O}_{3}$ composition. All samples were subject to the same processing conditions and all samples reached a minimum post-CIP density of $55 \mathrm{wt} \%$ of theory (TD).

Two sintering schedules were investigated for both metastable $\mathrm{NiO} \cdot 3 \mathrm{Al}_{2} \mathrm{O}_{3}$ and ball-milled $\mathrm{NiAl}_{2} \mathrm{O}_{4}+\mathrm{Al}_{2} \mathrm{O}_{3}$. The first schedule (H1) was a $10 \mathrm{~h}$ isothermal hold at $1400{ }^{\circ} \mathrm{C}$, which produced samples at least $95 \% \mathrm{TD}$, which is assumed to be sufficient for HIPing to $100 \%$ TD. Ramp rates are discussed in the experimental section above.

To investigate the role of phase transformation on sintering behavior and final microstructure, a second heating schedule (H2) was investigated. The second heating schedule was designed to fully demix the samples prior to densification and minimize grain growth through lower temperature sintering. Further isothermal sintering was performed until densification

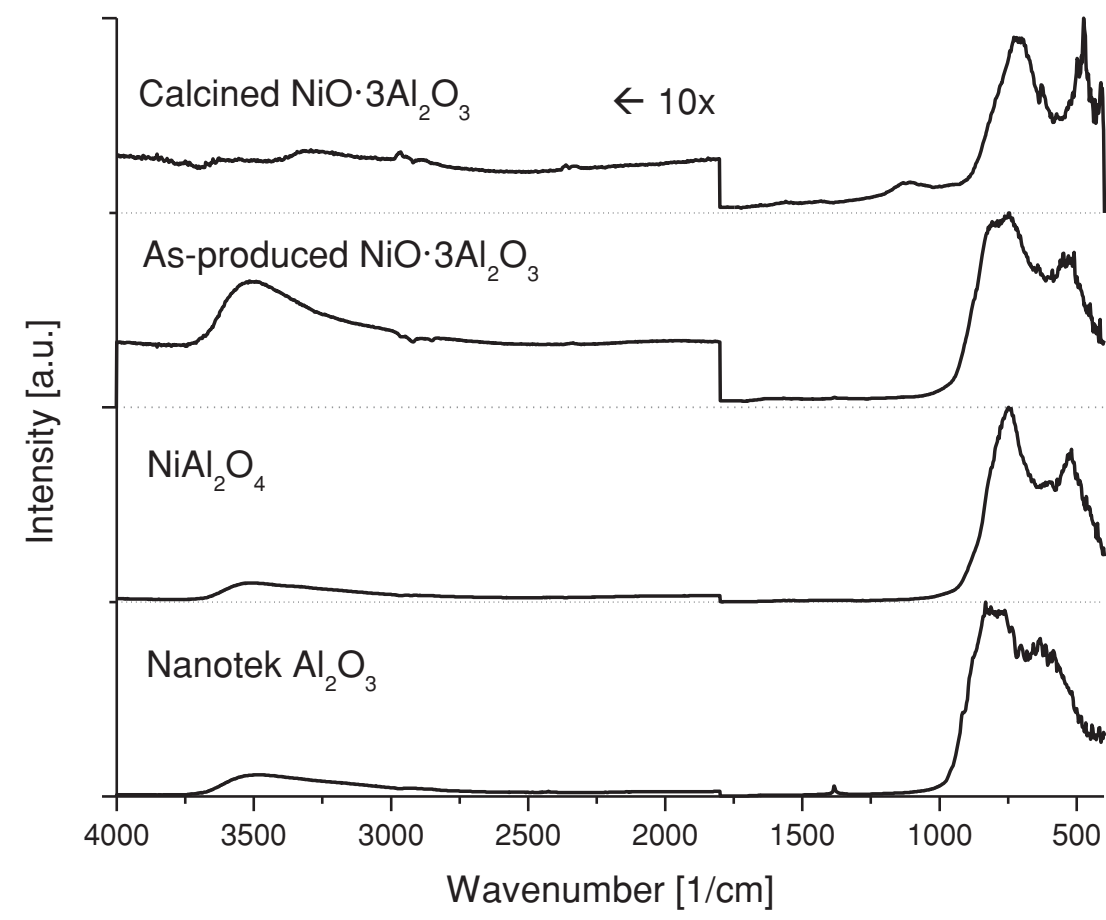

Figure 6. DRIFTS spectra for as-produced $\mathrm{NiO} \cdot 3 \mathrm{Al}_{2} \mathrm{O}_{3}, \mathrm{NiO} \cdot 3 \mathrm{Al}_{2} \mathrm{O}_{3}$ calcined for $2 \mathrm{~h} / 1150{ }^{\circ} \mathrm{C} /$ air, LF-FSP stoichiometric $\mathrm{NiAl}_{2} \mathrm{O}_{4}$, and Nanotek $\mathrm{Al}_{2} \mathrm{O}_{3}$. 
a)

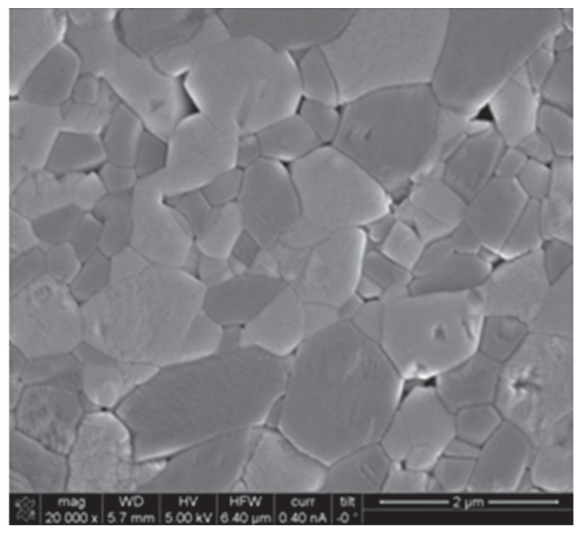

b)

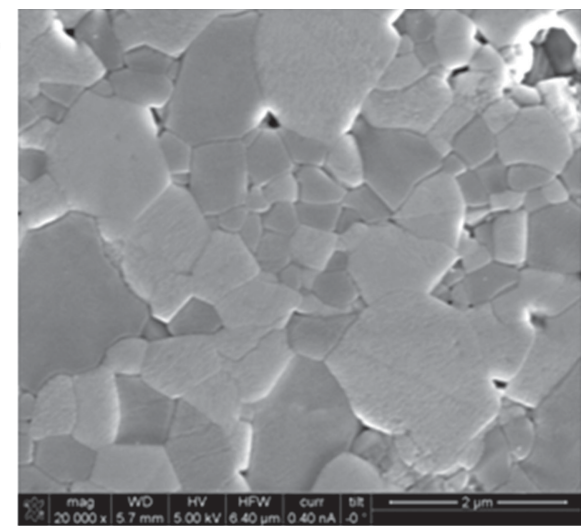

c)

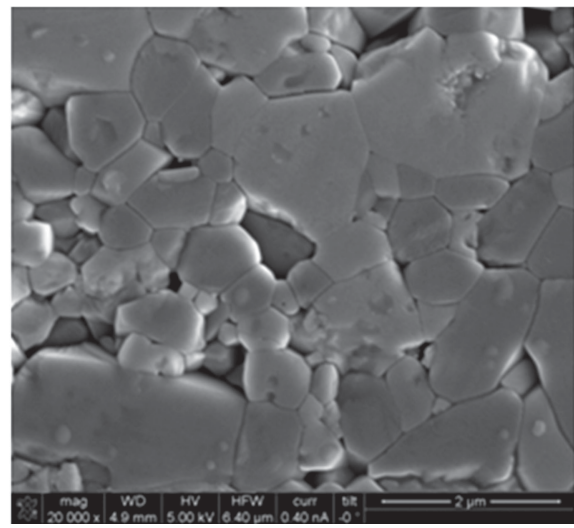

d)

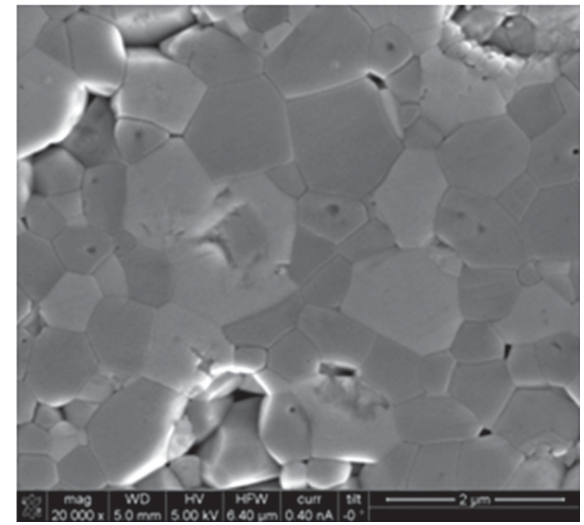

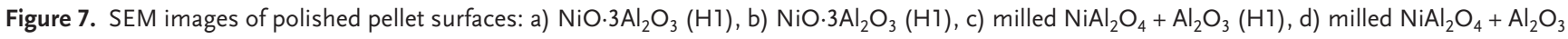
$(\mathrm{H} 2)$.

stopped, at which point the sintering temperature was raised. The second heating schedule was at $1150{ }^{\circ} \mathrm{C} / 4 \mathrm{~h}, 1300{ }^{\circ} \mathrm{C} / 8 \mathrm{~h}$, and $1400{ }^{\circ} \mathrm{C} / 4 \mathrm{~h}$, which also produced samples at least $95 \mathrm{wt} \%$ TD. The sintering studies were performed in dry $\mathrm{N}_{2}$, vacuum, and air, and no differences in densification or grain sizes were observed. Diffusion in $\mathrm{Al}_{2} \mathrm{O}_{3}$ rich spinels is dominated by cation-vacancy movement, so low $\mathrm{pO}_{2}$ should have no effect on sintering behavior. ${ }^{[18]}$

Figure 7 provides SEM images of polished pellet cross sections. Table 2 records post-CIP green densities, final densities, and average grain sizes (AGSs) as determined by the lineal intercept. AGSs for all sintered samples were $<1 \mu \mathrm{m}$ at densities greater than $95 \%$ TD.

Extensive SEM investigation of the polished samples found no noticeable differences in final microstructure. This observation is significant, given the length scales of initial phase separation in the starting materials. As noted above, while the $\mathrm{NiO} \cdot 3 \mathrm{Al}_{2} \mathrm{O}_{3}$ powders were atomically mixed, the ball-milled $\mathrm{NiAl}_{2} \mathrm{O}_{4}+\mathrm{Al}_{2} \mathrm{O}_{3}$ samples were mixed at significantly longer length scales.
Given that the individual APSs are 30-40 nm, we do not believe that it is possible by simply ball milling to achieve uniform mixing at length scales finer than submicrometer.

In an effort to determine if there were subtle differences between the two materials during densification, we undertook dilatometry studies. As seen Figures S4 and S5 there are no obvious differences in the densification temperatures or processes between the two approaches. This result alone is quite surprising but further studies remain to explore this issue and will be presented at a later date.

\section{Conclusions}

Dense $\alpha-\mathrm{Al}_{2} \mathrm{O}_{3} / \mathrm{NiAl}_{2} \mathrm{O}_{4}$ nanocomposites were prepared from both atomically mixed single phase $\mathrm{NiO} \cdot 3 \mathrm{Al}_{2} \mathrm{O}_{3}$ nanopowders and ball milled mixtures of $\mathrm{NiAl}_{2} \mathrm{O}_{4}$ and $\mathrm{Al}_{2} \mathrm{O}_{3}$ nanopowders produced by LF-FSP. Processing and sintering $\mathrm{NiO} \cdot 3 \mathrm{Al}_{2} \mathrm{O}_{3}$ gave composites at $95 \% \mathrm{TD}$ gave final microstructures, average grain sizes, and densification behavior that was identical to that

Table 2. Sintering conditions and final densities with average grain sizes for both composites.

\begin{tabular}{|c|c|c|c|c|c|}
\hline Composition & $\mathrm{TD}\left(\mathrm{g} \mathrm{cm}^{-3}\right)$ & CIP density \%TD & Heating schedule & Final density \%TD & Average grain size $(\mathrm{nm})$ \\
\hline $\mathrm{NiO} \cdot 3 \mathrm{Al}_{2} \mathrm{O}_{3}$ & 4.16 & $55 \% \pm 0.8 \%$ & $1400^{\circ} \mathrm{C}-10 \mathrm{~h}$ & $95 \% \pm 0.9 \%$ & $910 \pm 170$ \\
\hline $\mathrm{NiAl}_{2} \mathrm{O}_{4}+\mathrm{Al}_{2} \mathrm{O}_{3}$ & 4.16 & $57 \% \pm 1.2 \%$ & $1400^{\circ} \mathrm{C}-10 \mathrm{~h}$ & $96 \% \pm 0.8 \%$ & $870 \pm 208$ \\
\hline
\end{tabular}


of $\mathrm{NiO} \cdot 3 \mathrm{Al}_{2} \mathrm{O}_{3}$ composites produced through ball milling of nanopowders. The resultant composites have a range of possible applications, but this study represents a look at the synthesis and processing pathway needed to reach the finest, most uniform microstructure.

The bottom-up approach, as it stands, is one of the cornerstones of new material development; yet the synthesis of bulk materials from the bottom up is a underdeveloped field. In this work, we have shown one example of the synthesis of a bulk composite from the bottom-up that does not provide an advantage over a more traditional processing approach. The attractive properties of highly-dispersed, fine grained ceramic composite materials will continue to drive investigation in this field, and more complete studies of phase evolution and densification behavior may outweigh attention to highly atomically-mixed starting materials.

A related paper on processing atomically mixed $\mathrm{Y}_{3} \mathrm{Al}_{5} \mathrm{O}_{12} \mathrm{vs}$ ball milled 3:5 mixtures of $\mathrm{Y}_{2} \mathrm{O}_{3}$ and $\mathrm{Al}_{2} \mathrm{O}_{3}$ also provides results that greatly contrast with the bottom-up axiom. ${ }^{[32]}$

In future papers, we will discuss LF-FSP studies of analogous spinel composite systems, including $\mathrm{MgAl}_{2} \mathrm{O}_{4} / \mathrm{Al}_{2} \mathrm{O}_{4}$ and $\mathrm{CoAl}_{2} \mathrm{O}_{4} / \mathrm{Al}_{2} \mathrm{O}_{4}$ as well as binary $\mathrm{Y}_{3} \mathrm{Al}_{5} \mathrm{O}_{12} / \mathrm{Al}_{2} \mathrm{O}_{3}, \mathrm{Y}_{3} \mathrm{Al}_{5} \mathrm{O}_{12} /$ $\mathrm{MgAl}_{2} \mathrm{O}_{4}$, and ternary $\mathrm{Y}_{3} \mathrm{Al}_{5} \mathrm{O}_{12} / \mathrm{Al}_{2} \mathrm{O}_{3} / \mathrm{ZrO}_{2}$ composites. ${ }^{[33]}$

\section{Experimental Section}

Precursors: Alumatrane was synthesized as described elsewhere.[28] Anhydrous ethanol was purchased from Decon Labs (King of Prussia, PA). Nickel acetate was purchased from Sigma Aldrich (Milwaukee, WI) and used as received. Nanotek $\mathrm{Al}_{2} \mathrm{O}_{3}$ (Nanophase Technologies Corporation, Romeoville, IL) was received as a gift.

LF-FSP: Precursors were dissolved in ethanol solutions at less than $3 \mathrm{wt} \%$ ceramic loading. Solutions were aerosolized with $40 \mathrm{ml} / \mathrm{min}$ of extra dry $\mathrm{O}_{2}$ at 80 psi. $150 \mathrm{~mL} \mathrm{~min}-1$ of shield $\mathrm{O}_{2}$ was injected at 80 psi. Powders were collected in electrostatic precipitators with a $10 \mathrm{kV} \mathrm{DC}$ pseudopotential.

Powder Processing: Approximately $30 \mathrm{~g}$ of as-produced $\mathrm{NiO} \cdot 3 \mathrm{Al}_{2} \mathrm{O}_{3}$ LF-FSP powder was added to $350 \mathrm{~mL}$ of ethanol, with $2 \mathrm{wt} \%$ bicine as a dispersant and ball milled for $24 \mathrm{~h}$ with $3 \mathrm{~mm} 99 \%$ pure $\mathrm{Al}_{2} \mathrm{O}_{3}$ media. The suspension was ultrasonicated for 20 min using a Vibracell VC-505 ultrasonic horn (Sonics \& Materials, Newtown, CT) at $100 \mathrm{~W}$ of power. After a $24 \mathrm{~h}$ settling period, the supernatant was decanted and dried. The dried powders were sieved through a $75 \mu \mathrm{m}$ polymer mesh and dispersed in an ethanol solution with 4 wt \% PEC 3400 as binder. The dried powders were sieved through $20 \mu \mathrm{m}$ polymer mesh, uniaxially pressed at $14 \mathrm{MPa}$, and CIP'd to $200 \mathrm{MPa}$. Ball milled $\mathrm{NiO} \cdot 3 \mathrm{Al}_{2} \mathrm{O}_{3}$ composites were processed under identical conditions, except undergoing ultrasonication and settling prior to ball milling to ensure stoichiometry was maintained.

Burnout and Sintering: Pellets were burned out at $3^{\circ} \mathrm{C} \mathrm{min}^{-1}$ to $500{ }^{\circ} \mathrm{C}$

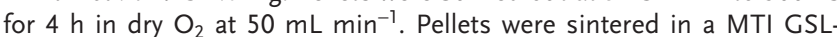
1600X (MTI Corp., Richmond, CA) tube furnace under flowing dry air at $50 \mathrm{~mL} \mathrm{~min}{ }^{-1}$. All sintering ramp rates were $10^{\circ} \mathrm{C} \mathrm{min}^{-1}$ below $1100^{\circ} \mathrm{C}$, and $5{ }^{\circ} \mathrm{C} \mathrm{min}^{-1}$ above $1100^{\circ} \mathrm{C}$.

$X$-ray Diffraction $(X R D)$ : X-ray diffraction was performed on a highintensity Rigaku rotating anode at $40 \mathrm{kV}$ and $100 \mathrm{~mA}$ (Rigaku USA, The Woodlands, TX). Sample scans were taken from $10-70^{\circ} 2 \theta$ with $0.02^{\circ}$ intervals and scanned at a rate of $2.0^{\circ} 2 \theta \mathrm{min}^{-1}$. X-ray patterns were analyzed using JADE 10.0. Vegard's law calculations were performed using an internal Si (111) standard. The lattice constant calculated from the (400) peak was 0.7980 , and was compared to a $\delta-\mathrm{Al}_{2} \mathrm{O}_{3}$ lattice constant of $0.7900 \mathrm{~nm}$ and a $\mathrm{NiAl}_{2} \mathrm{O}_{4}$ lattice constant of $0.8050 \mathrm{~nm}$.
Scanning Electron Microscopy (SEM): SEM was performed using a FEI Nova Nanolab dualbeam SEM/FIB (FEI Corporation, Hillsboro, OR) equipped with a Schottky FEG. Powders were dropped onto conductive copper tape on a sample stub. Samples were polished using normal laboratory techniques.

Transmission Electron Microscopy (TEM): TEM was performed on a JEOL 3011 HREM (JEOL Ltd., Tokyo, Japan) at $300 \mathrm{kV}$. Powders were dispersed in ethanol and wicked through a holey carbon grid.

Surface Area Analysis: SSA's were obtained on a Micromeritics ASAP 2020 sorption analyzer (Norcross, GA). Samples were degassed for $8 \mathrm{~h}$ at $400{ }^{\circ} \mathrm{C}$. Analysis was conducted on $\approx 200 \mathrm{mg}$ samples at $77 \mathrm{~K}$ with $\mathrm{N}_{2}$ adsorbate gas. SSA's were calculated using an 11 point BET method with relative pressures from $0.05-0.35$.

Thermogravimetric Analysis-Differential Thermal Analysis (TCA-DTA): Simultaneous TGA-DTA was performed on a Q600 TGA-DTA instrument (TA Instruments, Inc., New Castle, DE). Measurements were taken under $60 \mathrm{~mL} \mathrm{~min}{ }^{-1}$ of compressed extra dry air. Samples $(20-40 \mathrm{mg}$ ) were pressed in a $3 \mathrm{~mm}$ die and placed in an alumina sample pan. The reference pan was alumina. Samples were heated at $10{ }^{\circ} \mathrm{C} \mathrm{min}^{-1}$ to $1400^{\circ} \mathrm{C}$.

Diffuse Reflectance Infrared Fourier Transform Spectroscopy (DRIFTS): DRIFTS spectra were recorded on a ThermoScientific Nicolet 6700 FTIR spectrometer (ThermoScientific, Waltham, MA). Samples were prepared by grinding $5 \mathrm{mg}$ of sample in $400 \mathrm{mg}$ of optical grade $\mathrm{KBr}$ (International Crystal Laboratories, Garfield, NJ). Spectra were taken from $4000-400 \mathrm{~cm}^{-1}$ with a resolution of $\pm 4 \mathrm{~cm}^{-1}$ with an average of 60 scans. The sample chamber was continuously flushed with $N_{2}$ to minimize $\mathrm{CO}_{2}$ adsorption. New blank $\mathrm{KBr}$ reference samples were run every five samples.

Dilatometry: Dilatometry was run using a Theta Industries Dilatatronic II (Port Washington, NY) with a LVDT single push-rod loading dilatometry setup. Data were collected with a LabView progam. Square samples were sectioned from $14.7 \mathrm{~mm}$ diameter pellets formed as described above. Constant heating rate experiments were conducted with a heating rate of $10^{\circ} \mathrm{C} \mathrm{min}-1$ to $1500{ }^{\circ} \mathrm{C}$ in static air.

\section{Supporting Information}

Supporting Information is available from the Wiley Online Library or from the author.

\section{Acknowledgements}

The authors gratefully acknowledge the support of the NSF through DMR 1105361

Received: August 13, 2013

Revised: December 22, 2013

Published online: February 12, 2014

[1] C. M. Lieber, MRS Bulletin. 2003, 28, 486.

[2] L. Zhi, K. Mullen, J. Mater. Chem. 2008, 18, 1472.

[3] R. Murugavel, H. G. Walawalkar, M. Dan, H. W. Roesky, C. N. R. Rao, Acc. Chem. Res. 2004, 37, 763.

[4] L. G. Hubert-Pfalzgraf, J. Mater. Chem. 2004, 14, 3113.

[5] W. Lu, C. M. Lieber, Nat. Mater. 2007, 6, 841.

[6] J. Binner, B. Vaidhyanathan, J. Eur. Ceram. Soc. 2008, 28, 1329.

[7] R. Ramaseshan, S. Sundarrajan, R. Jose, S. Ramakrishna, J. App. Phys. 2007, 102, 111101

[8] S. Komarneni, J. Mater. Chem. 1992, 2, 1219.

[9] J. A. Azurdia, J. Marchal, P. Shea, H. Sun, X. Q. Pan, R. M. Laine, Chem. Mater. 2006, 18, 731.

[10] T. R. Hinklin, R. M. Laine, Chem. Mater. 2008, 20, 553.

[11] J. Azurdia, J. Marchal, R. M. Laine, J. Am. Ceram. Soc. 2006, 89, 2749. 
[12] T. R. Hinklin). A. Azurdia, M. Kim, J. C. Marchal, S. Kumar, R. M. Laine, Adv. Mater. 2008, 20, 1373.

[13] M. Kim, R. M. Laine, J. Am. Ceram. Soc. 2010, 93, 709.

[14] R. J. Hill, J. R. Craig, G. V. Gibbs, Phys. Chem. Mater. 1979, $4,3$.

[15] K. Mocala, A. Navrotsky, J. Am. Ceram. Soc. 1989, 17, 826.

[16] T. Hinklin, B. Toury, C. Gervais, F. Babonneau, J. J. Gisalon, R. W. Morton, R. M. Laine, Chem. Mater. 2004, 16, 21

[17] I. Levin, D. Brandon, J. Am. Ceram. Soc. 1998, 81, 1995.

[18] Y. Okuyama, N. Kurita, N. Fukatsu, Solid State lonics 2006, 177, 59.

[19] C.-J. Ting, H.-Y. Lu, J. Am. Ceram. Soc. 1999, 82, 841.

[20] N. M. Deraz, I. J. Electrochem. Sci. 2013, 8, 5203.

[21] Y. S. Han, J. B. Li, X. S. Ning, B. Chi, J. Am. Ceram. Soc. 2005, 88, 3455.

[22] S. Kurien, J. Mathew, S. Sebastian, S. N. Potty, K. C. George, Mater. Chem. Phys. 2006, 98, 470.

[23] A. Reyes-Rojas, H. E. Esparza-Ponce, J. Reyes-Gasga, J. Phys.: Condens. Matter 2006, 18, 4685
[24] J. R. H. Ross, M. C. F. Steel, A. Zeini-Isfahani, J. Catal. 1978, 52, 280.

[25] C. Otero Areán, M. Peñarroya Mentruit, A. J. López López, J. B. Parra, Colloids Surf. A 2001, 180, 253.

[26] D.-K. Kim, W. M. Kriven, J. Am. Ceram. Soc. 2008, 91, 784.

[27] B. W. Hoffer, A. Dick van Langeveld, J.-P. Janssens, R. L. C. Bonné, C. M. Lok, J. A. Moulijn, J. Catal. 2000, 192, 432.

[28] R. Baranwal, M. P. Villar, R. Garcia, R. M. Laine, J. Am. Ceram. Soc. 2001, 84, 951.

[29] M. Ozawa, O. Kato, S. Suzuki, Y. Hattori, M. Yamamura, J. Mater. Sci. Lett. 1996, 15, 564.

[30] G. de Roos, J. M. Fluit, J. H. W. de Wit, J. W. Gues, Surf. and Interf. Analysis 1981, 3, 221.

[31] P. Tarte, Spectrochim. Acta. 1967, 23A, 2127.

[32] N. J. Taylor, R. M. Laine, Adv. Funct. Mater. 2013, DOI: 10.1002/ adfm. 201301290.

[33] N. J. Taylor, A. J. Pottebaum, V. Uz, R. M. Laine, unpublished. 